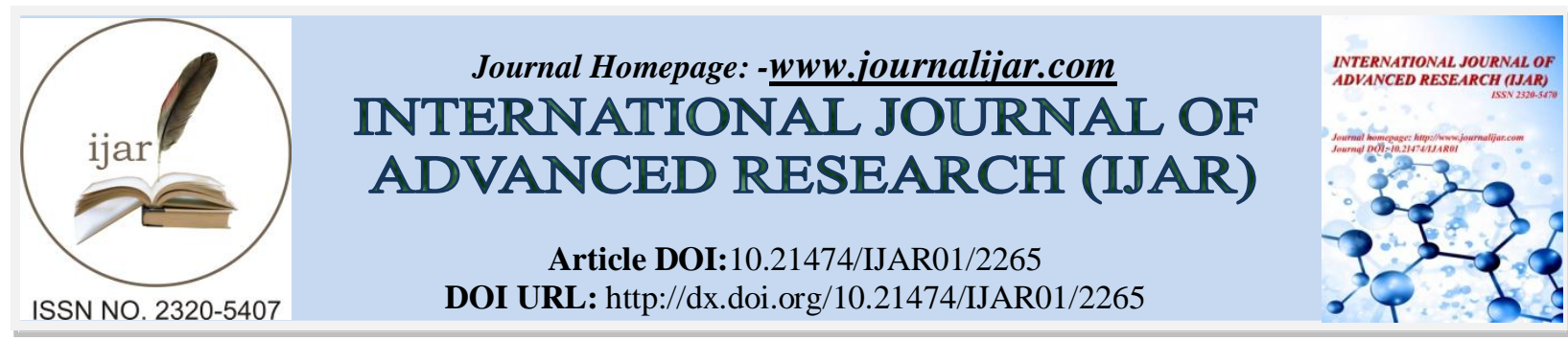

RESEARCH ARTICLE

\title{
NEONATAL SEPSIS IN A TERTIARY CARE HOSPITAL IN SAUDI ARABIA.
}

\author{
Abdulaziz S. Alrafiaah ${ }^{1}$, Mohammad Al Shaalan ${ }^{2}$, Faris O. Alshammari ${ }^{1}$, Ali A. Almohaisani ${ }^{1}$, Abdulrahman \\ S. Bawazir ${ }^{3}$ and Aamir Omair ${ }^{4}$. \\ 1. College of Medicine, King Saud Bin Abdulaziz University for Health Sciences, Riyadh, Saudi Arabia. \\ 2. King Abdullah Specialized Children's Hospital Riyadh, Saudi Arabia. \\ 3. College of Medicine, King Saud University, Riyadh, Saudi Arabia. \\ 4. Department of Medical Education, College of Medicine, King Saud Bin Abdulaziz University for Health \\ Sciences Riyadh, Saudi Arabia.
}

\section{Manuscript Info}

Manuscript History

Received: 29 September 2016

Final Accepted: 30 October 2016

Published: November 2016

Key words:-

Sepsis; Neonates; Neonatal Infections

\section{Abstract}

Background: The frequency of neonatal sepsis cases and their causative organisms vary from one hospital to another. This study aimed to identify the incidence of neonatal sepsis, causative organisms and their antibiotics susceptibility in King Abdulaziz Medical City in Riyadh (KAMC-R)

Methods: This cross-sectional study included neonates who were born in KAMC-R and had positive blood cultures during the year of 2014 within the first 90 days of life.

Results: Among 85 neonates with positive blood cultures 43 (51\%) had documented sepsis in their charts. Out of these 43 neonates 17 (40\%) had early-onset sepsis and 26 (60\%) had late-onset sepsis. Respiratory distress was found to be the most frequent presentation (79\%). Overall coagulase-negative Staphylococcus (CONS) was the commonest causative organism $(n=15,35 \%)$, however in early onset sepsis Escherichia coli (E. coli) was the most prevalent organism $(n=5,29 \%)$. The antibiotics that exhibited a high degree of sensitivity among gram negative and gram positive isolates were meropenem $(91.7 \%)$ and vancomycin (100\%), respectively. There were 6 out of 15 Gram negative bacilli isolates (40\%) that were extended spectrum beta lactamse (ESBL) producers. The infection with gram-negative organisms was more likely to be associated with poor outcome with five (33\%) deaths out of 15 cases as compared to one (4\%) death out of 25 gram-positive cases $(\mathrm{p}=0.02)$.

Conclusion:The majority of neonatal sepsis cases in our hospital were caused by gram-positive bacteria, with CONS being the most isolated organism. However, gram-negative bacteria were associated with higher rates of mortality.

Copy Right, IJAR, 2016,. All rights reserved.

\section{Introduction:-}

Neonatal sepsis is a serious infection that is a major concern for its high rate of mortality and its association with severe complications if not recognized and treated early [1]. It is defined by the presence of a positive blood culture 
in association with systemic signs and symptoms of infection [2,3]. The clinical presentation of neonatal sepsis can be subtle and variable depending on the age of the patient and the causative organism [4]. The classification of neonatal sepsis is based on the time of onset. Early-onset sepsis occurs in the first seven days of life and is mainly caused by organisms that colonize maternal genital tract. Late-onset sepsis appears after one week and up to three months of age, and it can be either nosocomial or community-acquired [5].

The incidence of early neonatal sepsis in the United States was 0.76 cases per 1,000 live births in 2008 [6]. Compared to early onset sepsis, the incidence of late onset sepsis is higher with one study conducted in Taiwan reporting a cumulative incidence of 3.71 episodes per 1000 neonate-days in a period from 2004-2011 [7]. Multiple organisms have been known to cause neonatal sepsis; these include coagulase-negative Staphylococcus (CONS), E. coli, Group B Streptococci (GBS) and Candida species [8-10]. In a review study conducted by Tosson and Speer that included studies from eight Arab countries on the causative organisms of neonatal sepsis, it was found that CONS and Staphylococcus aureus (S.aureus) were predominant in Saudi Arabia [11]. In Yemen, however, AlShamahy et al. reported that Klebsiella pneumoniae was the most frequent pathogen, followed by Pseudomonas species [12].

Risk factors that increase the likelihood of neonatal sepsis include low socioeconomic conditions, prematurity, low birth weight, and prolonged rupture of membranes [13, 14].Additionally, a study conducted in neonates with earlyonset neonatal sepsis revealed that premature rupture of membrane (PROM), meconium stained amniotic fluid, and foul smelling liquor were significantly associated with the development of neonatal sepsis [13]. Several studies have reported that prematurity and low birth weight are associated with increased risk of mortality in patients with sepsis $[10,15-17]$.

Due to the clinical importance of this topic and the scarcity of data related to it in Saudi Arabia, this study aimed to identify the incidence of neonatal sepsis, causative organisms and their antibiotics susceptibility in King Abdulaziz Medical City in Riyadh (KAMC-R).

\section{Methods:-}

This study was ethically approved by the Institutional Review Board at King Abdullah International Medical Research Center (KAIMRC), National Guard Health Affairs, Riyadh, Saudi Arabia. This is a cross sectional study carried out in the pediatric department in KAMC-R, which is a tertiary hospital located in Riyadh, Saudi Arabia. The data were obtained for pediatric patients aged 0-90 days who were admitted to the pediatric department during the year of 2014, including the pediatric wards, pediatric intensive care unit (PICU), neonatal intensive care unit (NICU) and nursery stepdown unit.

Patients with documented diagnoses of sepsis in their charts with positive blood cultures were included in the study. Only babies who were born in KAMC-R were included in order to extrapolate the incidence rate based on birth cohort in this facility. Any baby with contaminant blood culture or isolated bacteremia without clinical presentation that is suggestive of sepsis were excluded.

Positive blood cultures which fulfilled the study inclusion criteria were recruited from the microbiology laboratory in the hospital. The microbiological profiles of the causative organisms and their antibiotics susceptibility were acquired from the laboratory results. Additional variables were collected from the files of the infants; these variables included gestational age, birth weight, any complications during gestation or delivery, the age of the infant at the time of presentation, gender, clinical presentation, and the patient's outcome.

The data were entered and analyzed using Statistical Package for Social Sciences (SPSS, version 22). The categorical variables are presented as frequencies and percentages while the numerical variables are presented as mean \pm standard deviation, or median and interquartile range for skewed data. The mortality was compared with early and late onset neonatal sepsis and the type of the bacteria (gram-positive and gram-negative) using the ChiSquare test. A p-value $<0.05$ was considered statistically significant for all the statistical tests.

\section{Results:-}

A total of 109 positive blood cultures were obtained from the microbiology lab. Twenty-four neonates were excluded because they were not born in KAMC-R. Upon review of the patients' files and exclusion of babies with 
contaminant blood cultures or asymptomatic bacteremia, 43 (51\%) of the remaining 85 neonates were diagnosed with sepsis as documented in their charts. The results of this study were derived from those 43 patients who fit the inclusion criteria of the study. The demographics of babies who had sepsis are presented in (Table 1).

Table 1:-Demographics of babies with neonatal sepsis $(\mathrm{N}=43)$

\begin{tabular}{|c|c|c|}
\hline Gender & $\begin{array}{r}\text { Male } \\
\text { Female }\end{array}$ & $\begin{array}{l}25(58 \%) \\
18(42 \%)\end{array}$ \\
\hline Gestational Age group & $\begin{array}{r}\text { Preterm }(<37 \text { weeks }) \\
\text { Term }(\geq 37 \text { weeks })\end{array}$ & $\begin{array}{l}30(70 \%) \\
13(30 \%)\end{array}$ \\
\hline Gestational age at delivery (in weeks) & $31.4 \pm 6$ & \\
\hline Birth weight (in grams) & $\begin{array}{r}\text { Mean } \underline{ \pm s d} \\
\text { Median (IQR) }\end{array}$ & $\begin{array}{c}1753.1 \pm 1081.4 \\
1440(745,2870)\end{array}$ \\
\hline Age at time of presentation (in days) & $\begin{array}{r}\text { Mean } \pm \text { sd } \\
\text { Median (IQR) }\end{array}$ & $\begin{array}{c}17.8 \pm 18.9 \\
10(2,27)\end{array}$ \\
\hline
\end{tabular}

Infants who developed sepsis in the first seven days of their lives were classified as early-onset sepsis, and they comprised $40 \%(\mathrm{n}=17)$, whereas the remaining $60 \%(\mathrm{n}=26)$ had late-onset sepsis as they presented between 8-90 days. Based on a birth cohort of 8665 in the year of 2014 at KAMC-R, this will be translated to an incidence rate of early onset sepsis of 1.96 per 1000 births $(95 \% \mathrm{CI}=1.03,2.89)$ and late onset sepsis of 3.0 per 1000 live births $(95 \% \mathrm{CI}=1.85,4.15)$. Seven cases of early-onset neonatal sepsis were associated with documented maternal risk factors in their files; PROM was found in four of these cases. The other maternal risk factors included maternal fever, GBS colonization and chorioamnionitis. The most common clinical presentation that was recorded for the patients included in this study was respiratory distress $(n=34,79 \%)$ as shown in Figure 1.

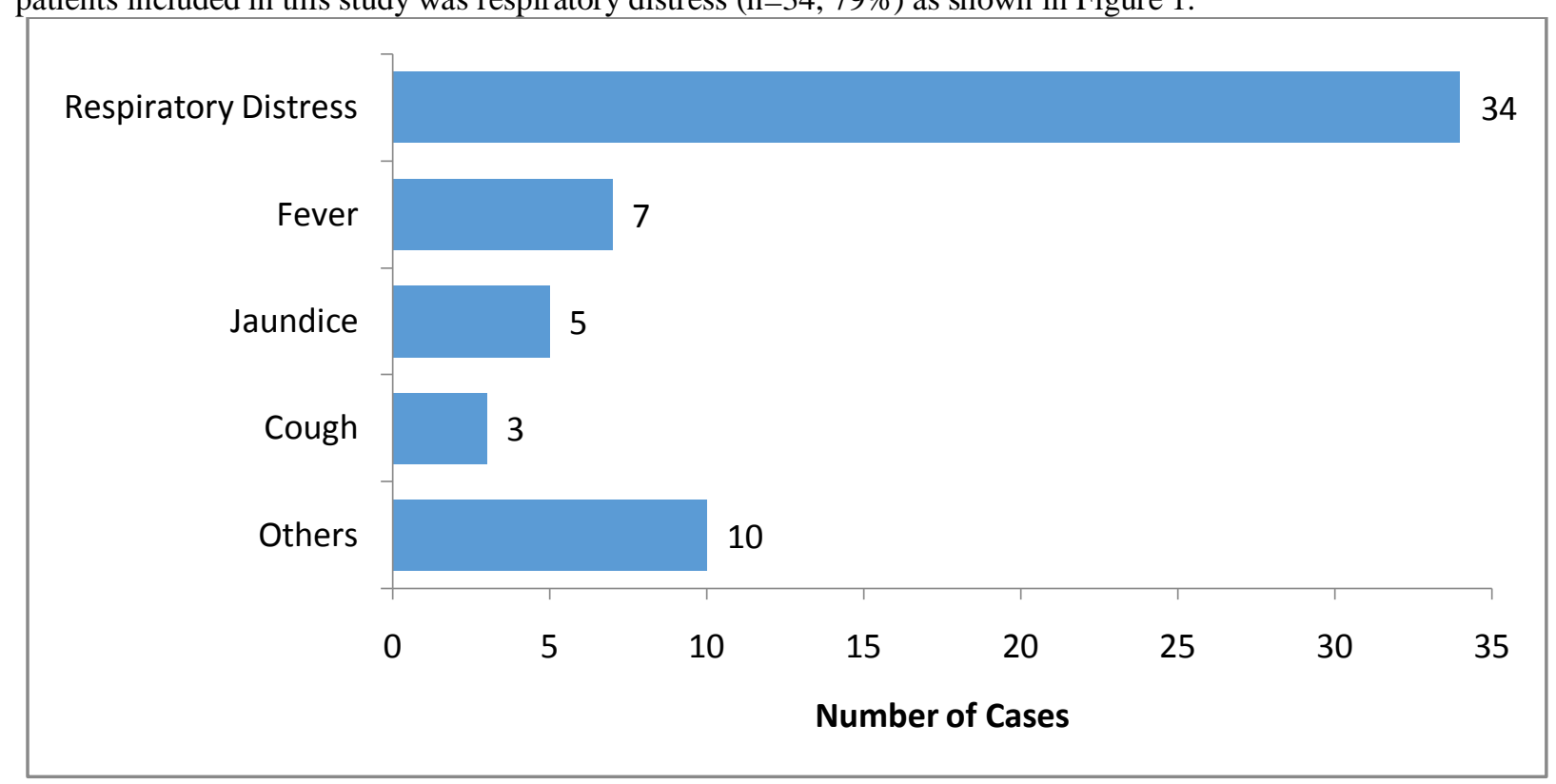

Figure 1:- Clinical presentation of babies with neonatal sepsis* $(\mathrm{N}=43)$

* More than one clinical presentation possible

With regards to the causative organisms of neonatal sepsis, Coagulase-negative Staphylococcus(CONS) was found to be the most prevalent organism causing neonatal sepsis in term and preterm babies, accounting for $35 \%(\mathrm{n}=15)$ of the cases followed by E. coli $(n=5,12 \%)$ (Table 2). The distribution of the causative organisms in early and late sepsis are shown in Figure 2 and 3, respectively. 
Table 2:- Causative organisms of neonatal sepsis in term and preterm babies $(\mathrm{N}=43)$

\begin{tabular}{|c|c|c|c|}
\hline Organism & Total $(n=43)$ & $\begin{array}{c}\text { Preterm } \\
(\mathrm{n}=30)\end{array}$ & $\begin{array}{c}\text { Term } \\
(n=13)\end{array}$ \\
\hline Gram positive bacteria & 25 & 16 & 9 \\
\hline Coagulase-negative Staphylococcus & $15(35 \%)$ & $12(40 \%)$ & $3(23 \%)$ \\
\hline Staphylococcus aureus & $4(9 \%)$ & $2(7 \%)$ & $2(15 \%)$ \\
\hline Group B Streptococcus (GBS) & $3(7 \%)$ & & $3(23 \%)$ \\
\hline Streptococcus viridans & $2(5 \%)$ & $2(7 \%)$ & \\
\hline Methicillin-resistant Staphylococcus aureus(MRSA) & $1(2 \%)$ & & $1(8 \%)$ \\
\hline Gram negative bacteria & 15 & 11 & 4 \\
\hline Escherichia coli & $5(12 \%)$ & $4(13 \%)$ & $1(8 \%)$ \\
\hline Pseudomonas aeruginosa & $4(9 \%)$ & $4(13 \%)$ & \\
\hline Klebsiella pneumoniae & $3(7 \%)$ & $1(3 \%)$ & $2(15 \%)$ \\
\hline Acinetobacterbaumannii & $1(2 \%)$ & $1(3 \%)$ & \\
\hline Pantoea & $1(2 \%)$ & & $1(8 \%)$ \\
\hline Enterobacter cloacae & $1(2 \%)$ & $1(3 \%)$ & \\
\hline Fungal & 3 & 3 & \\
\hline Candida species & $3(7 \%)$ & $3(10 \%)$ & \\
\hline
\end{tabular}

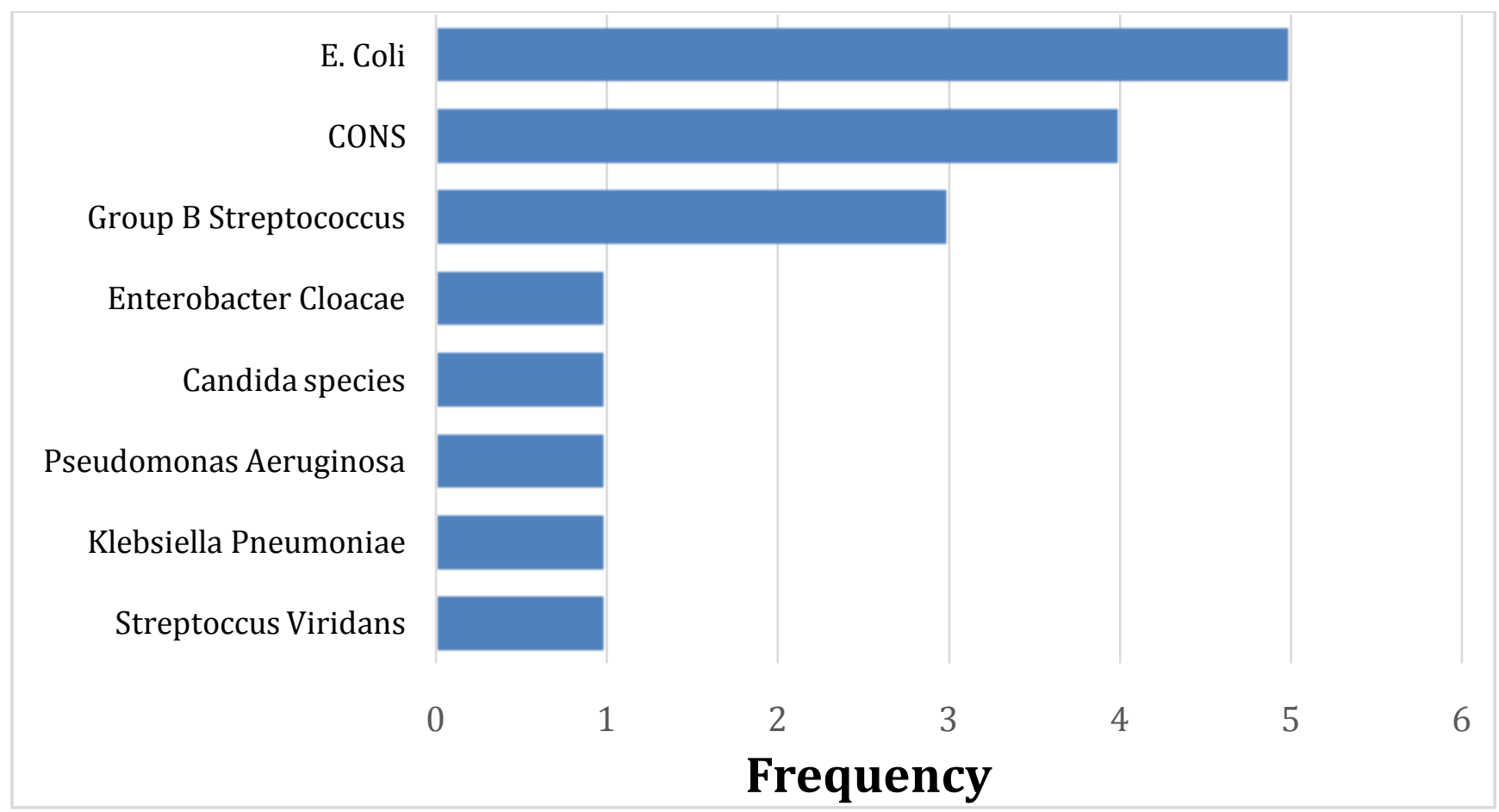

Figure 2:- Causative organisms of early onset neonatal sepsis $(\mathrm{N}=17)$ 


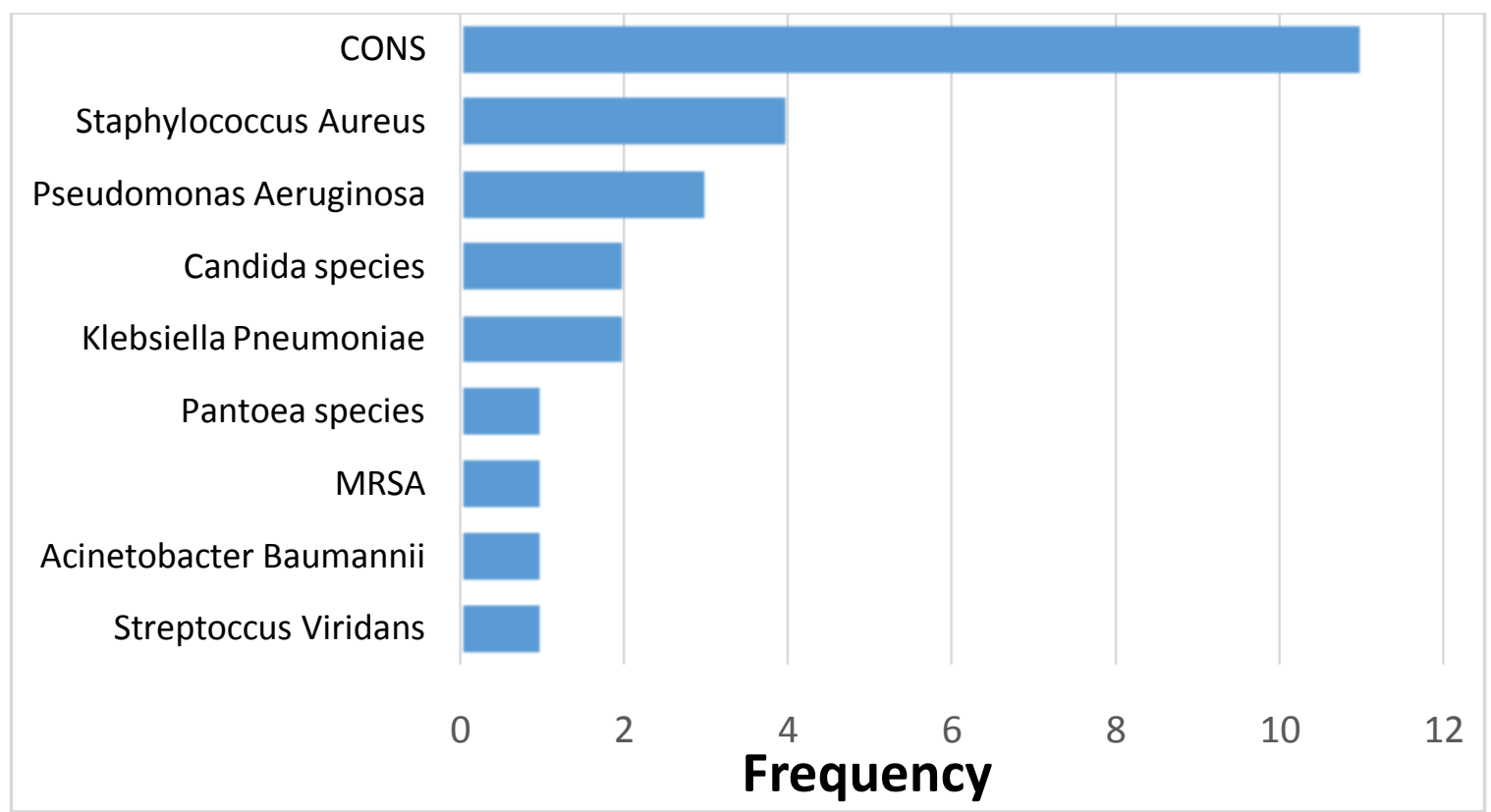

Figure 3:- Causative organisms of late onset neonatal sepsis $(\mathrm{N}=26)$

The antibiotics susceptibility of the isolated gram positive organisms was assessed in the majority of the sample (19 out of 25 gram positive isolates) using oxacillin, clindamycin, trimethoprim/sulfamethoxazole (TMP/SMX) and vancomycin. The sensitivity of these antibiotics against gram positive organisms was as follow; oxacillin (26.3\%), clindamycin (36.8\%), trimethoprim/sulfamethoxazole (89.5\%), and vancomycin (100\%). In gram negative organisms; gentamicin, meropenem, and ciprofloxacin were tested on 12 out 15 gram negative isolates.Best overall sensitivity against gram negative organisms was meropenem $(91.7 \%)$, followed by gentamicin (83.3\%) and ciprofloxacin (83.3\%). There were 6 out of 15 Gram negative bacilli isolates (40\%) that were extended spectrum beta lactamse (ESBL) producers including; two Klebseilla pneumonia, two E. coli, one Pantoea species and one Enterobacter cloacae. All of these organisms were sensitive to meropenem except one organism which was Klebsiella pneumoniae carbapenemase-producing K. pneumoniae (KPC-Kp).

There were a total of seven (16\%) deaths out of 43 cases of neonatal sepsis. The details of these seven cases are shown in table 3. All of the seven deaths were in preterm babies $(n=30)$, while there was no death in babies born at term $(n=13)$ showing a borderline association $(\mathrm{p}=0.06)$. Four of these deaths happened in neonates who presented with early onset neonatal sepsis $(n=17)$ as compared to three deaths in those who presented with late sepsis $(n=26)$, showing no significant association $(\mathrm{p}=0.27)$. The comparison of deaths between the gram negative and gram positive infected cases showed a higher mortality in gram negative cases $(\mathrm{p}=0.02)$.

Table 3:- characteristics of dead neonates with sepsis $(\mathrm{N}=7)$

\begin{tabular}{|c|c|c|c|c|c|}
\hline $\mathrm{N}$ & $\begin{array}{l}\text { Gestational age } \\
\text { (in weeks) }\end{array}$ & $\begin{array}{l}\text { Birth weight (in } \\
\text { grams) }\end{array}$ & $\begin{array}{c}\text { Age at time of } \\
\text { presentation (in days) }\end{array}$ & Gender & Organism \\
\hline 1 & 22 & 700 & 11 & Male & $\begin{array}{c}\text { Pseudomonas } \\
\text { aeruginosa }\end{array}$ \\
\hline 2 & 23 & 530 & 4 & Female & Candida albicans \\
\hline 3 & 24 & 780 & 0 & Male & E. coli \\
\hline 4 & 26 & 758 & 5 & Male & $\begin{array}{c}\text { Pseudomonas } \\
\text { aeruginosa }\end{array}$ \\
\hline 5 & 31 & 1780 & 26 & Female & Klebsiella pneumoniae \\
\hline 6 & 32 & 1440 & 5 & Female & $\begin{array}{l}\text { E. coli } \\
\end{array}$ \\
\hline 7 & 35 & 1790 & 55 & Male & $\begin{array}{c}\text { Coagulase-negative } \\
\text { Staphylococcus }\end{array}$ \\
\hline
\end{tabular}




\section{Discussion:-}

Neonatal sepsis continues to be one of the major leading cause of morbidity and mortality in newborns. The causative organisms of neonatal sepsis are varied from one region to another, and they are changing over time. Despite the developments that we currently have in the medical filed, the diagnosis of neonatal sepsis can be challenging and it mostly relies on the clinical suspicion and the presence of positive blood culture. The clinical signs and symptoms of neonatal sepsis are nonspecific which makes it difficult to be diagnosed. The distribution of early and late onset sepsis has been reported differently in multiple studies. In our study, it was found that late-onset sepsis was more common than early sepsis. Similar results were reported in Taiwan where $72 \%$ of the cases had late-onset sepsis [18], while early sepsis was more prevalent in a study conducted in India comprising 57\% of the included sample [19].

Prematurity and low birth weight were profound in newborns who had sepsis in our study, and this is similar to the findings of previous studies on neonatal sepsis conducted internationally and regionally [19-21]. Thus, special attention should be directed to babies with prematurity and low birth weight as they are more predisposed to develop neonatal sepsis, and appropriate empirical therapy should be started as early as possible. Moreover, measures to decrease the risk of prematurity and its complications could contribute significantly to decrease the incidence of neonatal sepsis. Various maternal risk factors that predispose to the development of early neonatal sepsis were investigated with PROM being the most common maternal risk factor in this study, and it is consistent with the results reported in a study done in Cameroon [22].

Since the clinical picture of neonatal sepsis can be variable and overlapping with other diseases, reporting the common signs and symptoms associated with neonatal sepsis can be beneficial in the early identification of the affected babies. Our results have showed that most patients with neonatal sepsis presented with respiratory distress, and this is comparable to the results of a study conducted recently in Egypt [21]. In contrast, Chiabi et al. have found that fever and irritability are more frequent than respiratory distress [22].

The reported microbiological etiologies showed that CONS is the major causative pathogen in our sample. While several studies reached similar results to ours [21, 23-25], other studies from other developing countries have reported that gram-negative bacteria constituted the majority of the causative organisms of neonatal sepsis [26-28]. Our study showed that $35 \%$ of neonatal sepsis were caused by different types of gram-negative bacteria, with E. coli being the predominant one. E. coli was also found to be the main pathogen causing early sepsis, and this is consistent with the findings of Kilani and Basamad in a study from Riyadh published in 2000 [24]. Almost one third of isolated Gram negative bacilli in this study were ESBL producer. In many reports, 25-50\% of Gram negative sepsis was caused by multidrug resistant organisms $[19,29,30]=$. This is especially noticed in developing countries. The most plausible explanation for such rise is related to inappropriate use of antibiotics, antibiotic under dosing, prolonged use of antibiotics, frequent use of combined antibiotics and lack of stewardship programs. Infection by gram-negative bacteria was associated with a higher rate of mortality in comparison to gram-positive bacterial infection. This could be attributed to multiple factors including increased virulence, prematurity, comorbidities, and inappropriate or delayed initial empiric therapy. Although CONS constitutes the highest percentage of neonatal sepsis in our hospital, it causes less severe disease and it is mostly related to inserted devices e.g. central lines. Three cases of neonatal sepsis in this study were caused by fungal infections, and all of them occurred exclusively in premature babies. This obviously related to the immature immune system of those neonates which made them more predisposed for such opportunistic infections.

There were some limitations to this study. The small sample size that was recruited can limit the power of the study. Additionally, we chose to be limited to babies born in KAMC-R only in order to have inclusive clinical information as well as to be able to extrapolate the incidence of neonatal sepsis in our institution.

In conclusion, the results of this study revealed that coagulase-negative Staphylococcus (CONS) accounted for the majority of neonatal sepsis cases in our hospital. Gram-negative bacteria, however, were associated with higher rates of mortality. Nearly halve of isolated gram-negative bacilli causing neonatal sepsis were multidrug resistant organisms.

\section{Declaration of Interest:-}

The authors have declared that no competing interests exist. 


\section{References:-}

1. Al-Taiar A, Hammoud MS, Thalib L, Isaacs D. Pattern and etiology of culture-proven early-onset neonatal sepsis: a five-year prospective study. Int J Infect Dis. 2011;15(9):e631-4.

2. Li Z, Xiao Z, Li Z, Zhong Q, Zhang Y, Xu F. 116 cases of neonatal early-onset or late-onset sepsis: A single center retrospective analysis on pathogenic bacteria species distribution and antimicrobial susceptibility. Int $\mathbf{J}$ Clin Exp Med. 2013;6(8):693-9.

3. Shin YJ, Ki M, Foxman B. Epidemiology of neonatal sepsis in South Korea. Pediatr Int. 2009;51(2):225-32.

4. Sharma CM, Agrawal RP, Sharan H, Kumar B, Sharma D, Bhatia SS. "Neonatal Sepsis": Bacteria \& their Susceptibility Pattern towards Antibiotics in Neonatal Intensive Care Unit. J Clin Diagn Res. 2013;7(11):25113.

5. Isaacs D. Evidence-based neonatal infections. BMJ Books. Chichester: John Wiley \& Sons. 2014. Ch.2: p.6. Available from: http://www.alsendibad.net/uploads/8/7...ce-based_neonatal_infections_2014.pdf

6. Weston EJ, Pondo T, Lewis MM, Martell-Cleary P, Morin C, Jewell B, et al. The burden of invasive early-onset neonatal sepsis in the United States, 2005-2008. Pediatr Infect Dis J. 2011;30(11):937-41.

7. Tsai MH, Hsu JF, Chu SM, Lien R, Huang HR, Chiang MC, Fu RH, Lee CW, Huang YC. Incidence, clinical characteristics and risk factors for adverse outcome in neonates with late-onset sepsis. Pediatr Infect Dis J. 2014;33(1):e7-e13.

8. Le Doare K, Heath PT. An overview of global GBS epidemiology. Vaccine. 2013;31 Suppl 4:D7-12.

9. Najeeb S, Gillani S, Rizvi SK, Ullah R, ur Rehman A. Causative bacteria and antibiotic resistance in neonatal sepsis. J Ayub Med Coll Abbottabad. 2012;24(3-4):131-4.

10. Simonsen KA, Anderson-Berry AL, Delair SF, Davies HD. Early-onset neonatal sepsis. Clin Microbiol Rev. 2014;27(1):21-47.

11. Tosson AM, Speer CP. Microbial pathogens causative of neonatal sepsis in Arabic countries. J Matern Fetal Neonatal Med. 2011;24(8):990-4.

12. Al-Shamahy HA, Sabrah AA, Al-Robasi AB, Naser SM. Types of Bacteria associated with Neonatal Sepsis in Al-Thawra University Hospital, Sana'a, Yemen, and their Antimicrobial Profile. Sultan Qaboos Univ Med J. 2012;12(1):48-54.

13. Shah GS, Budhathoki S, Das BK, Mandal RN. Risk factors in early neonatal sepsis. Kathmandu Univ Med J (KUMJ). 2006;4(2):187-91.

14. Waliullah MS, Islam MN, Siddika M, Hossain MK, Hossain MA. Risk factors, clinical manifestation and bacteriological profile of neonatal sepsis in a tertiary level pediatric hospital. Mymensingh Med J. 2009;18(1 Suppl):S66-72.

15. Lin CB, Hornik CP, Clark R, Cotten CM, Benjamin DK, Jr., Cohen-Wolkoweiz M, et al. Very low birth weight neonates who survive early-onset sepsis do not have an increased risk of developing late-onset sepsis. Early Hum Dev. 2012;88(11):905-9.

16. Stoll BJ, Hansen N, Fanaroff AA, Wright LL, Carlo WA, Ehrenkranz RA, et al. Changes in pathogens causing early-onset sepsis in very-low-birth-weight infants. N Engl J Med. 2002;347(4):240-7.

17. Stoll BJ, Hansen N, Fanaroff AA, Wright LL, Carlo WA, Ehrenkranz RA, et al. Late-onset sepsis in very low birth weight neonates: the experience of the NICHD Neonatal Research Network. Pediatrics. 2002;110(2 Pt 1):285-91.

18. Jiang JH, Chiu NC, Huang FY, Kao HA, Hsu CH, Hung HY, et al. Neonatal sepsis in the neonatal intensive care unit: characteristics of early versus late onset. J Microbiol Immunol Infect. 2004;37(5):301-6.

19. Mehar V, Yadav D, Somani P, Bhatambare G, Mulye S, Singh K. Neonatal sepsis in a tertiary care center in central India: microbiological profile, antimicrobial sensitivity pattern and outcome. J Neonatal Perinatal Med. 2013;6(2):165-72.

20. Afsharpaiman S, Torkaman M, Saburi A, Farzaampur A, Amirsalari S, Kavehmanesh Z. Trends in incidence of neonatal sepsis and antibiotic susceptibility of causative agents in two neonatal intensive care units in tehran, I.R iran. J Clin Neonatol. 2012;1(3):124-30.

21. Shehab El-Din EM, El-Sokkary MM, Bassiouny MR, Hassan R. Epidemiology of Neonatal Sepsis and Implicated Pathogens: A Study from Egypt. Biomed Res Int. 2015;2015:509484.

22. Chiabi A, Djoupomb M, Mah E, Nguefack S, Mbuagbaw L, Zafack J, et al. The clinical and bacteriogical spectrum of neonatal sepsis in a tertiary hospital in yaounde, cameroon. Iran J Pediatr. 2011;21(4):441-8.

23. Hammoud MS, Al-Taiar A, Thalib L, Al-Sweih N, Pathan S, Isaacs D. Incidence, aetiology and resistance of late-onset neonatal sepsis: a five-year prospective study. J Paediatr Child Health. 2012;48(7):604-9.

24. Kilani RA, Basamad M. Pattern of proven bacterial sepsis in a neonatal intensive care unit in Riyadh-Saudi Arabia: a 2-year analysis. J Med Liban. 2000;48(2):77-83. 
25. Thapa B, Thapa A, Aryal DR, Thapa K, Pun A, Khanal S, et al. Neonatal sepsis as a major cause of morbidity in a tertiary center in Kathmandu. JNMA J Nepal Med Assoc. 2013;52(192):549-56.

26. Karambin M, Zarkesh M. Entrobacter, the most common pathogen of neonatal septicemia in rasht, iran. Iran J Pediatr. 2011;21(1):83-7.

27. Shitaye D, Asrat D, Woldeamanuel Y, Worku B. Risk factors and etiology of neonatal sepsis in Tikur Anbessa University Hospital, Ethiopia. Ethiop Med J. 2010;48(1):11-21.

28. West BA, Peterside O. Sensitivity pattern among bacterial isolates in neonatal septicaemia in port Harcourt. Ann Clin Microbiol Antimicrob. 2012;11:7.

29. Chandel DS, Johnson JA, Chaudhry R, Sharma N, Shinkre N, Parida S, et al. Extended-spectrum betalactamase-producing Gram-negative bacteria causing neonatal sepsis in India in rural and urban settings. J Med Microbiol. 2011;60(Pt 4):500-7.

30. Srivastava R, Agarwal J, Srivastava S, Kumar M, Singh M. Multidrug resistant Gram-negative bacilli from neonatal septicaemia at a tertiary care centre in North India: a phenotypic and genotypic study. Indian J Med Microbiol. 2014;32(1):97-8. 